\title{
O RELEVANTE PAPEL DA EXTENSÃO UNIVERSITÁRIA: UM RELATO DE CASO NA PRODUÇÃO DE ÁLCOOL-GEL PARA DOAÇÃO A VULNERÁVEIS NO COMBATE AO CORONAVÍRUS
}

DOI: 10.37702/2175-957X.COBENGE.2021.3645

Natal Junio Pires - natal.fg@gmail.com

Centro Federal de Educação Tecnológica de Minas Gerais

Rua das Candeias 235

38181-330 - Araxá - MG

Antônio Lenito Soares Júnior - alsoaresjr@gmail.com

Centro Federal de Educação Tecnológica de Minas Gerais

Av. Ministro Olavo Drummond 25

38180-510 - Araxá - MG

João Victor da Silva Alves - joaoalves.araxa@gmail.com

CEFET

Av. Ministro Olavo Drummond, 2525

38180-510 - ARAXA - MG

Maria Virgínia da Cunha - mariavcunha01@gmail.com

CEFETMG

Rua João Limírio da Silva 314

38170-000 - Perdizes - MG

Guilherme Otávio dos Santos - guielh@gmail.com

UFMG

Rua João Verçosa 267

38183-070 - Araxa - MG

Resumo: Nas atividades extensionistas os discentes têm a oportunidade de retribuir a sociedade civil algo relevante e, assim, buscar uma menor desigualdade social. Além da formação de ensino e pesquisa de qualidade é fundamental que o discente possa trabalhar os conhecimentos adquiridos na forma de projetos de extensão, pois são neles que frequentemente as ações efetivas aos cidadãos mais vulneráveis estão evidenciadas. Sendo assim, estar preparado para responder aos 
anseios mais urgentes em termos de demanda social, assim como de formação acadêmica é condição essencial para se atingir um nível de excelência em nossas universidades. Neste contexto de atender às demandas sociais, o projeto teve como objetivo principal produzir álcool-gel 70@INPM para assepsia da pele e desinfecção de superfícies e fazer a doação da produção a asilos e casas de cuidados a vulneráveis nas cidades de Araxá-MG e Perdizes-MG. Vale ressaltar que ação a de formação de indivíduos mais colaborativos e sensíveis as demandas dos mais carentes transcende ao objetivo de produzir e entregar o álcool-gel. A execução do projeto contou com a contribuição de dois docentes e três discentes da nossa instituição de ensino. $O$ desenvolvimento do projeto contou com várias etapas, como: estudo do projeto, produção do rótulo da embalagem, levantamento da rota de produção (foi adotado a formulação conforme preconizado no Formulário Nacional da Farmacopeia Brasileira), elaboração de oito Procedimentos Operacionais Padrão ( $\left.P O P^{\prime} s\right)$, treinamento técnico e de segurança da equipe, a efetiva produção do álcool-gel 70@INPM e a entrega da produção nos estabelecimentos beneficiados. Por conta dos discentes, além de todo o trabalho técnico e teórico no acréscimo das suas formações acadêmicas profissionais, a participação deles nesse ato trouxe como principal benefício o engajamento em uma ação concreta de enfrentamento a problemas sociais relevantes. Aos professores fica a certeza de renovação ao final do trabalho, pois toda ação nova traz novas experiências, novas vivências, novas perspectivas que fazem com que transformações ocorram e a retribuição à sociedade seja direta e imediata ao aderir a projetos extensionistas.

Palavras-chave: Projeto extensionista, coronavírus, álcool-gel 70\% ( $\mathrm{m} / \mathrm{m})$, formação complementar. 


\section{COBENGE \\ O RELEVANTE PAPEL DA EXTENSÃO UNIVERSITÁRIA: UM RELATO DE CASO NA PRODUÇÃO DE ÁLCOOL-GEL PARA DOAÇÃO A VULNERÁVEIS NO COMBATE AO CORONAVÍRUS}

\section{INTRODUÇÃO}

A Lei de Diretrizes e Bases da Educação Nacional (BRASIL, 1996), quando trata das finalidades da educação superior, traz em seu capítulo IV, artigo 43 e inciso VII, os seguintes dizeres: "promover a extensão, aberta à participação da população, visando à difusão das conquistas e benefícios resultantes da criação cultural e da pesquisa científica e tecnológica geradas na instituição". Em que pese a importância do ensino e pesquisa, não resta dúvida que a coroação de qualquer atividade universitária vem com essa função social de retribuir à sociedade que a financia um pouco do muito que é investido nas universidades públicas.

Além da imprescindível contribuição citada anteriormente, a extensão é também de fundamental importância para a formação acadêmica, pois soma-se à sua condição de espaço de oportunidade para os discentes colocarem em prática os seus conhecimentos (ASSIS, 2020). Ao assumir uma atividade extensionista, o aluno estará alcançando uma formação para a vida, dado que nessas condições ele se defronta com problemas reais que exigem várias habilidades importantes, tais como: trabalho em equipe, tomadas de decisão, organização de processos produtivos/colaborativos e outros mais; onde apenas o enfrentamento de situações adversas fora da academia o colocará no exercício pleno de sua atividade enquanto ser social.

No entanto, Rodrigues e colaboradores (2017) salientam que embora sejam muitos os recursos destinados para a atividade de extensão ainda são poucos os agentes professores e alunos - que incorporam o "espírito" extensionista na forma de proposição de projetos que tenham esse viés e, normalmente, por comodidade os projetos de pesquisa são tomados como preferidos, visto que eles não demandam tanta dedicação fora do espaço acadêmico. Tal conduta é, sem dúvida, ponto de questionamento, pois as universidades/agentes não estariam atendendo ao disposto no inciso supracitado da LDB. Além disso, entende-se que o corpo discente estaria recebendo uma formação "deficitária" tanto no âmbito profissional quanto no âmbito social ao não se envolver com atividades de extensão.

Sendo assim, estar preparado para responder aos anseios mais urgentes em termos de demanda social, bem como de formação acadêmica é condição essencial para se atingir um nível de excelência em nossas universidades. Enquanto o engajamento nas atividades extensionistas ficarem atreladas apenas a pequenos grupos proativos dentro do âmbito universitário, a formação desejada seguirá cambaleante e defasada (ASSIS, 2020). No fim, quem acaba por ter o maior prejuízo com isso é a própria sociedade, com retorno restrito de ações a partir de onde existe - a universidade - um potencial considerável para se conseguir minimizar desigualdades sociais.

No contexto de atender às demandas sociais na medida em que surgem as necessidades, foi apresentado o projeto de extensão intitulado: "Formulação de álcool-gel para assepsia da pele e desinfecção de superfícies", a ser desenvolvido em nossa instituição. O projeto foi proposto e supervisionado pelos docentes de uma unidade de ensino e para a execução e desenvolvimento contou-se com a colaboração dos alunos de graduação e pós-graduação do curso de Engenharia de Minas do nosso campus. 
Tal projeto teve origem no fato de que em março de 2020, ao ser declarada situação de pandemia global (Covid-19), o mundo e o nosso país iniciaram o enfrentamento de dificuldades sociais, ambientais, sanitárias e econômicas que até o presente momento ainda não foram superadas (CHAKRABORTY, 2020). Dessa forma, além do caráter perverso do vírus trazido à saúde pública, certamente, o ano de 2020 será lembrado na história do nosso país como o início de uma grande tragédia que acentua ainda mais a desigualdade social que há séculos assola considerável parte da sociedade. Num momento como esse, os indivíduos mais vulneráveis sofrem de forma impactante e desumana as consequências da herança cruel da falta de políticas capazes de atender e suprir necessidades tão básicas quanto a dignidade da vida.

Sensibilizados pela situação de iminente perigo à vida dos mais vulneráveis, o grupo formado por dois professores e três discentes atenderam a chamada para um edital de extensão lançado em nossa instituição através da sua Diretoria de Extensão e Desenvolvimento Comunitário (DEDC), proposto em caráter emergencial, visando o enfrentamento ao Covid-19. Então submeteu-se um projeto para viabilizar a produção de álcool-gel para assepsia da pele e desinfecção de superfícies, em que toda formulação produzida seria doada a asilos e casas de cuidados a vulneráveis nas cidades de AraxáMG e Perdizes-MG. Historicamente, essas instituições de auxílio se mantêm, em grande medida, com regimes de doações, e dado que a pandemia lhes impôs dificuldades maiores ainda, garantir a assepsia de todos que frequentam esses ambientes direta ou indiretamente, não é tarefa fácil, pois tem custos. Portanto, entende-se que a produção e doação do álcool-gel para estes estabelecimentos é socialmente relevante, pois de certa forma garante uma assepsia adequada das mãos daqueles que estão acondicionados nesses espaços (usuários e funcionários) diminuindo o risco de serem contaminados.

Neste artigo serão apresentadas as considerações acerca do projeto desenvolvido, bem como atuação dos extensionistas que dele participaram. Espera-se dessa forma contribuir para expor e reforçar à comunidade científica a importância do envolvimento de todos em ações como essas. A reflexão sobre a ação dentro da proposta do projeto eleva materialmente o papel da extensão e universidade no âmbito social, além da constatação de se alcançar uma formação sólida e ampla dos discentes nela envolvidos.

\section{METODOLOGIA}

Uma vez aprovado o projeto, deu-se início a ele através de uma conversa do coordenador e do coordenador adjunto com a equipe de alunos envolvidos na produção. Nela foi ressaltado a contribuição social do projeto de extensão e que essa ação representava uma forma de agradecimento à sociedade aos anos de estudo que receberam em uma instituição pública, mantida com os impostos do povo brasileiro. Em seguida passou-se ao treinamento da equipe, onde foram ressaltadas as boas práticas de fabricação, bem como os aspectos importantes relacionados ao controle de qualidade de produtos oriundos da indústria química. A partir daí, teve-se início a formulação do álcoolgel $70 \% \mathrm{~m} / \mathrm{m}$ (70 INPM) conforme preconizado no Formulário Nacional da Farmacopeia Brasileira (BRASIL, 2012). Após formulação foi realizado o envase dos lotes de álcool-gel em frasco plástico - PET, bem como a sua rotulação. No rótulo/embalagem constam a logomarca da instituição, CNPJ, endereço, validade do produto, concentração do álcool, indicação de uso, formulação qualitativa completa e as advertências gerais, em conformidade com a NOTA TÉCNICA № 3/2020/SEI/DIRE3/ANVISA (ANVISA, 2020). Após acompanhamento de estabilização de cada lote produzido - 72 horas - e análise microbiológica, estes foram liberados para entrega. A entrega foi realizada sempre com a 
presença da equipe extensionista do projeto. O desenvolvimento da ação de produção e entrega seguiu o esquema de demanda das instituições, ou seja, a produção foi continuada durante os 6 meses de duração do projeto à medida que as instituições de amparo precisavam repor seus estoques. O acompanhamento de todas as ações, desde a produção até a entrega do álcool-gel, foi realizado através de relatórios e registro de todas as atividades inerentes ao projeto, tais como controle de qualidade, preparação da formulação e entrega da produção. Relatórios quantitativos e qualitativos mensais dos dias de atuação da equipe no laboratório, bem como, das atividades de entrega das formulações com registro documental e fotográfico.

\section{RESULTADOS}

A seguir apresentaremos as etapas principais do projeto e como cada uma delas contribuiu para a formação profissional e humana dos envolvidos. A formação em ambos os aspectos pôde ser realizada em vários momentos do projeto dentro de um escopo de ações previamente delimitado pelos coordenadores. As principais ações que acreditamos estarem em destaque são apresentadas no esquema da figura 1.

Figura 1 - Esquema simplificado de ações de formação profissional dentro do projeto.

\begin{tabular}{|c|}
\hline Concepção, escrita e proposição do projeto \\
\hline Estruturação, elaboração e confecção do rótulo \\
\hline $\begin{array}{c}\text { Elaboração de protocolos com base nas boas } \\
\text { práticas de fabricação }\end{array}$ \\
\hline Treinamento técnico e de segurança da equipe \\
\hline Produção do álcool-gel 70 `INPM \\
\hline Entrega da produção nos estabelecimentos \\
beneficiados
\end{tabular}

Fonte: Elaborada pelos autores.

Em todas as etapas há uma infinidade de habilidades desenvolvidas pela equipe e que, sem dúvida, potencializa a formação acadêmica dos alunos, potencialização esta que dificilmente seria conquistada fora do alcance de um projeto de extensão.

\subsection{Concepção, escrita e proposição do projeto}

Uma vez publicado o edital em nossa instituição, os docentes submeteram a proposta à DEDC para que fosse feita sua avaliação. Com a aprovação do projeto, procedeu à seleção de discentes para compor a equipe através de chamada específica e ampla divulgação. Neste momento foram selecionados três alunos do curso de Engenharia de Minas, e ato contínuo Ihes foi apresentado o projeto em questão e, a partir daquele 
momento, passaram a fazer parte de todas as discussões subsequentes da ação proposta. Neste ponto puderam ter a primeira experiência importante. Embora os alunos não tenham participado efetivamente da fase de elaboração do projeto, puderam conhecê-lo na íntegra e em detalhes na apresentação do mesmo pelos coordenadores da ação.

\subsection{Estruturação, elaboração e confecção do rótulo}

Nesta ação teve-se a participação de toda a equipe que, em conjunto fez a leitura no disposto na NOTA TÉCNICA № 3/2020/SEI/DIRE3/ANVISA (ANVISA, 2020), de forma a proceder de acordo com a legislação vigente e assegurar que o rótulo contivesse todas as informações técnicas importantes para o usuário final do produto que ora seria preparado. O rótulo esboçado foi levado até um profissional de arte gráfica, o qual então fez a arte daquilo que seria usado nos frascos de álcool-gel produzidos. Na figura 2 é apresentado o resultado do que foi idealizado pela equipe e processado em arte gráfica.

Figura 2 - Rótulo idealizado pela equipe e processado em arte gráfica.
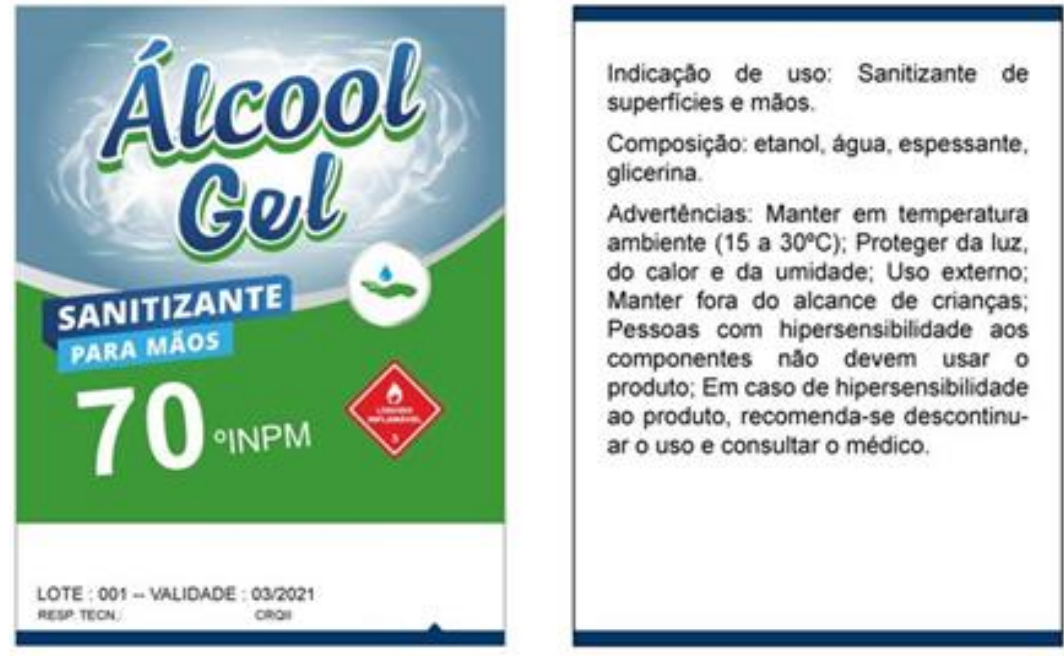

Fonte: Elaborada pelos autores.

Vale ressaltar que do rótulo da Figura 2 foram retirados os dados da nossa instituição, pois sua apresentação revelaria a afiliação dos autores. Com o rótulo foi destacado aos alunos a importância de obedecer à legislação e que um produto qualquer esteja em conformidade com aquilo que rege a prática dentro de certo campo profissional. Puderam perceber que caso não obedecido as normatizações o responsável técnico fica sujeito a ações penais inerentes ao nível de violação cometido. Ressalta-se aqui que, embora a ação extensionista neste caso tenha se dado na interface Química/Farmácia e não especificamente no campo da Engenharia de Minas, a necessidade de se debruçar sobre e seguir a legislação vigente independe do campo técnico considerado, e resguardas as especificidades de cada campo, a lógica da conduta é comum a todos. Além disso, os alunos envolvidos concluíram no decorrer do curso, vários créditos em disciplinas de Química. Dessa forma, puderam relembrar conceitos e colocar em prática boa parte daquilo que desenvolveram no aprendizado de seus estudos curriculares.

\subsection{Elaboração de protocolos com base nas boas práticas de fabricação}

Sem organização, o caos reina. Com base nessa premissa básica a equipe elaborou um total de oito POP's (Procedimentos Operacionais Padrão) para concretizar a produção 
da formulação de forma organizada e de modo a garantir a qualidade do produto. Os protocolos POP's são elencados no esquema mostrados na figura 3.

Figura 3 - Esquema simplificado de ações de formação profissional dentro do projeto.

POP1: Preparo e envase do álcool-gel 70 INPM

POP2: Procedimento de limpeza da área de produção e envase

POP3: Diluição do peróxido de hidrogênio 3\% v/v

POP4: Procedimento de fracionamento da matéria-prima sólida

POP5: Caderno de registro da formulação pronta e envase

POP6: Ficha de registro de treinamento da equipe

POP7: Ficha de procedimento para análise físico-química

POP8: Ficha de procedimento para análise microbiológica

Fonte: Elaborada pelos autores.

Organizar o trabalho de produção e roteirizar detalhadamente qualquer etapa do processo de produção é atividade indispensável a qualquer profissional da área de engenharia, e que é parte intrínseca da gestão de processos visando garantir o cumprimento de todas as etapas mais simples do processo até as mais complexas (Haider e Asif, 2012). Como duas das principais finalidades desta organização é a garantia da qualidade e melhoria dos produtos. Neste projeto de extensão os alunos participaram de forma ativa na elaboração dos POP's mostrados na figura 3, juntamente com os coordenadores, possibilitando assim o contato com essa ferramenta de gestão bem como a sua efetivação e correção mediante os resultados obtidos.

\subsection{Treinamento técnico e de segurança da equipe}

Toda a equipe envolvida recebeu o treinamento técnico dos coordenadores da ação. Tal proposta visou garantir que todas as etapas do processo fossem seguidas de forma rigorosa, sem colocar em risco a produção, bem como a integridade física dos indivíduos participantes dela. O etanol é um dos componentes principais da formulação, e sendo ele altamente combustível, sua manipulação exige cuidados bastante específicos, uma vez que qualquer procedimento equivocado aconteça, o risco de acidentes é iminente. Em qualquer área de atuação técnica, a garantia de que todas as etapas de projeto sejam executadas e certificadas de forma adequada é princípio básico da atividade profissional.

Quanto à segurança dos envolvidos, esta ganha relevância em qualquer projeto, e assim medidas preventivas que visem eliminar e/ou minimizar quaisquer riscos têm que ser levadas em consideração. Na maioria das empresas existem comissões e serviços 
especializados que cuidam especificamente de garantir que tais medidas sejam elaboradas e cumpridas. Portanto, tomar contato com essas ações dentro de um projeto de extensão, prepara o acadêmico que vai se deparar com essas práticas no seu campo profissional, e assim faz com que, antecipadamente, ele já perceba a importância prática em participar de treinamentos específicos dentro das corporações industriais.

\subsection{Produção do álcool-gel 70 INPM}

Uma vez elaborados os POP's e realizado o treinamento da equipe, procedeu-se à produção do primeiro de 3 lotes que foram executados durante o projeto. Em cada lote foram produzidos 50 litros de álcool-gel, totalizando assim os 150 litros proposto no projeto para distribuição em instituições carentes. Na figura 4 é apresenta de forma esquemática a parte de preparo da formulação no POP1.

Figura 4 - Fluxograma de preparação de componentes para a produção de álcool em gel 70\% para assepsia das mãos.
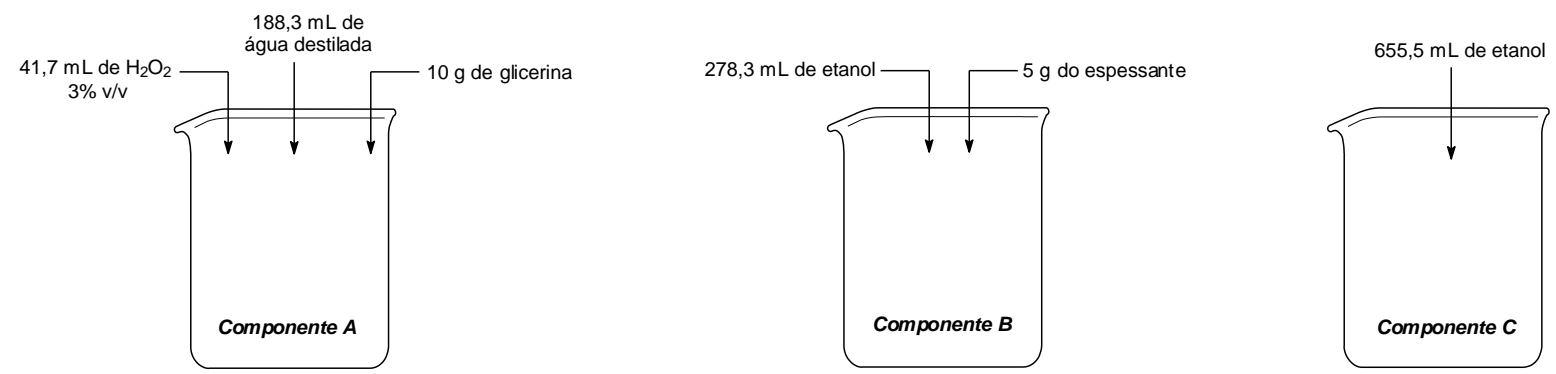

Fonte: Elaborada pelos autores.

Uma vez preparados os componentes descritos anteriormente, estes foram processados conforme apresentado na figura 5, para resultar na formulação pronta para envase. Durante a produção percebeu-se que o volume final de álcool-gel era menor que os volumes das substâncias líquidas misturadas inicialmente no processo.

Figura 5 - Fluxograma de mistura dos componentes para a produção de álcool em gel 70\% para assepsia das mãos.

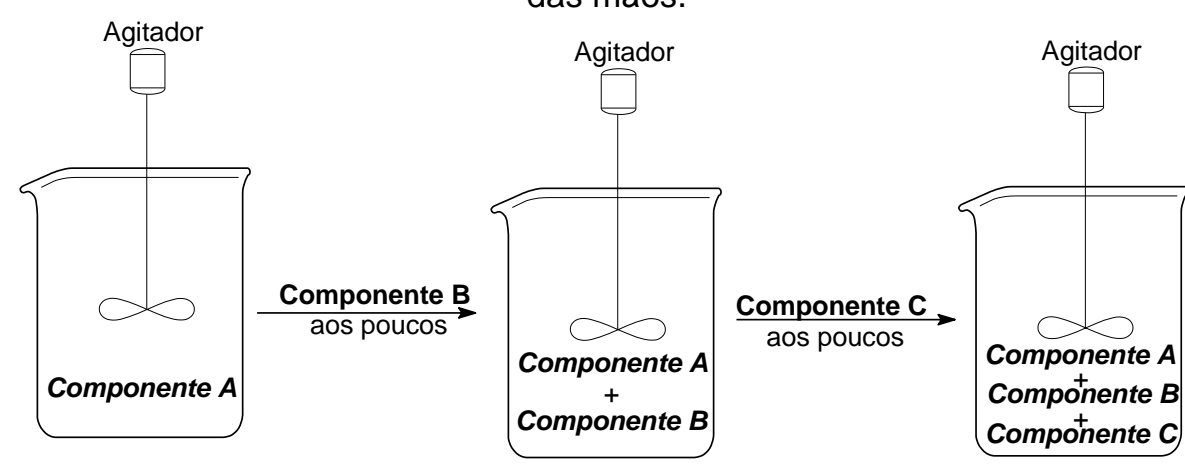


Nesse momento foram trabalhados e revisitados alguns conceitos químicos com os discentes participantes para dar respostas ao fato observado. Conceitos como ligações químicas, interações intermoleculares, energia de interações foram lembrados pelos alunos e, oportunamente, puderam perceber os conhecimentos teóricos "dialogando" diretamente com as observações práticas. Esse momento serviu para valorização dos estudos, às vezes de áreas não tão afins de sua carreira, na formação mais ampla de um engenheiro.

Após as etapas supracitadas a produção estava pronta para ser embalada e rotulada. Aguardou-se as 72 horas para a estabilização do coloide e, posteriormente, uma amostra do lote foi encaminhada para o controle físico-química e microbiológico. A figura 6 traz a foto do $1^{\circ}$ lote produzido no projeto.

Figura 6 - Primeiro lote de álcool-gel 70 INPM produzido pela equipe do projeto de extensão.

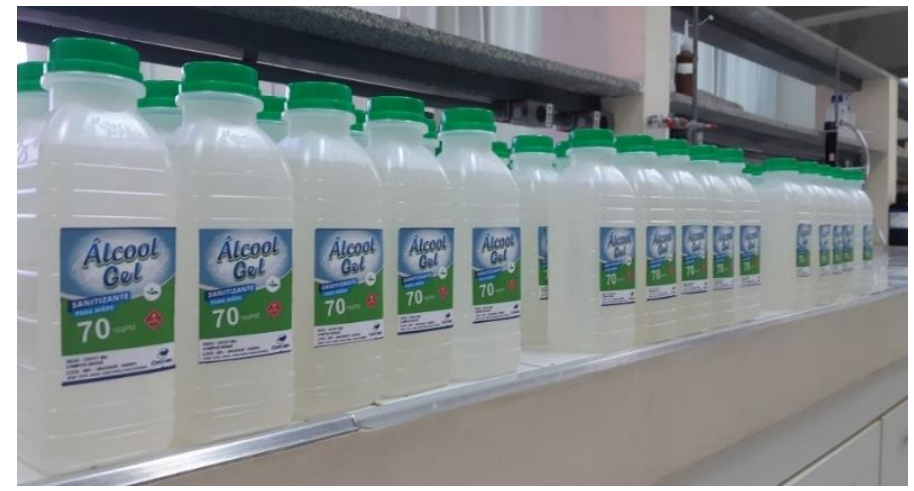

Fonte: Acervo dos autores.

A etapa da produção foi de suma importância para a equipe de alunos para que pudessem ver a concretização do trabalho oriundo de todo o planejamento prévio, bem como propor melhoras e ajustes no processo, algo também corriqueiro na prática profissional do engenheiro. Na figura 7 temos a foto da equipe em um dos momentos de trabalho na produção do $1^{\circ}$ lote de álcool-gel.

Figura 7 - Equipe do projeto de extensão produzindo o álcool-gel $70^{\circ}$ INPM do primeiro lote.

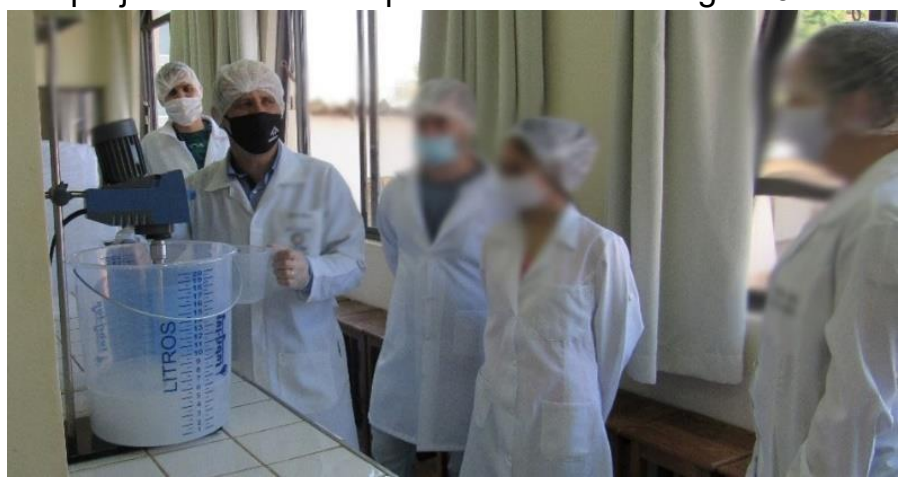

Fonte: Acervo dos autores.

\subsection{Entrega da produção nos estabelecimentos beneficiados}

A entrega dos lotes produzidos foi um dos momentos mais gratificantes para toda a equipe, pois foi o ponto de concretização do projeto. Ou seja, o momento que marca sobretudo a entrega do "produto final" com origem na universidade e seus membros àqueles que tanto já contribuíram com os impostos para o estado e hoje dependem do sistema como um todo 
para viver com dignidade a sua velhice. Nas figuras $8 \mathrm{a}, 8 \mathrm{~b}$ e $8 \mathrm{c}$ são mostradas as fotos da entrega do $1^{\circ}$ lote a três instituições cuidadoras de idosos e vulneráveis, as quais foram assistidas por este projeto de extensão.

Figura 8 - Foto da entrega do $1^{\circ}$ lote de álcool-gel ao: (a) Asilo São Vicente de Paula em Araxá-MG; (b) Asilo São Vicente de Paula em Perdizes-MG e (c) Instituto Acolher em Perdizes-MG.

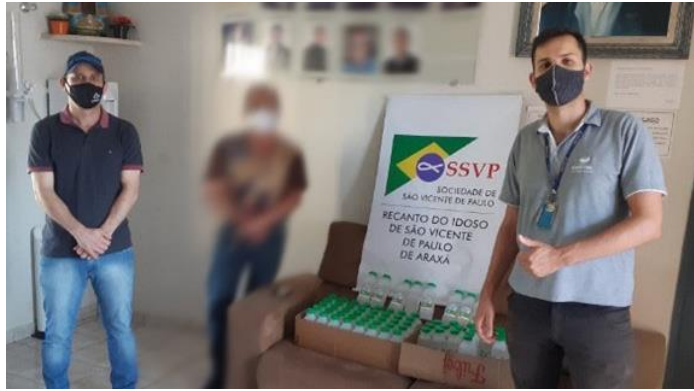

(a)

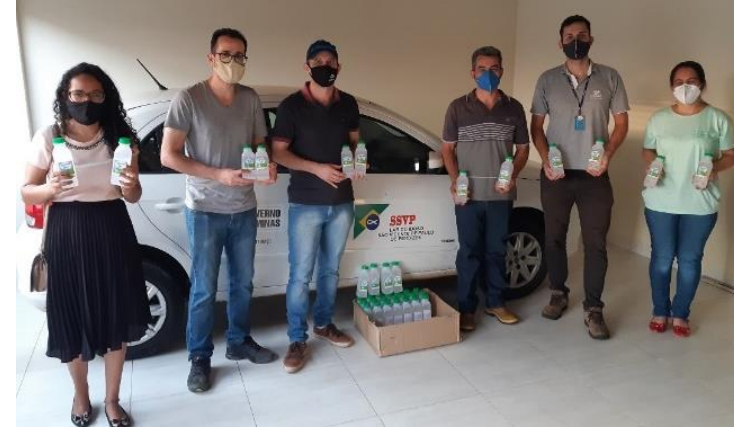

(b)

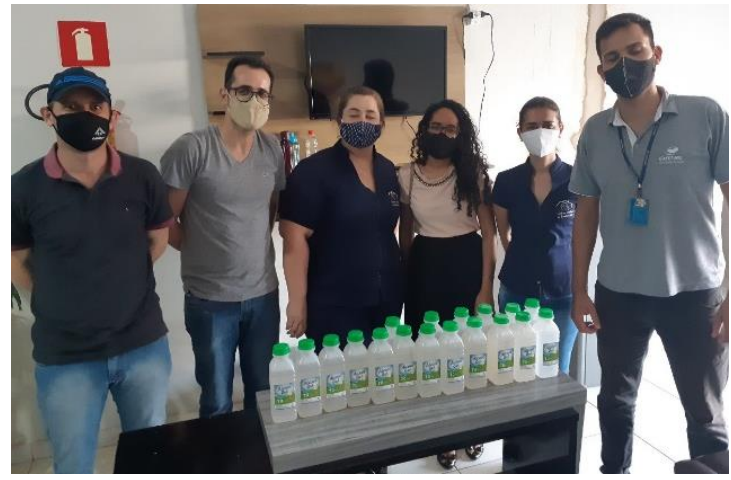

(c)

Fonte: Acervo dos autores.

Vale ressaltar que também foi ajudado um lar de crianças, que está dentro de um grupo de vulnerabilidade. Não houve o contato direto dos participantes com os idosos e vulneráveis, pois por se tratar de uma época de pandemia e com restrições sanitárias, foi necessário assegurar a integridade das pessoas que ali residiam. As entregas foram feitas aos responsáveis por gerir as instituições assistidas com o projeto.

Após a entrega do $1^{\circ}$ de três lotes a equipe de discentes pôde ter uma noção exata da dimensão daquilo a que se propuseram fazer, pois cada um dos responsáveis pelos ambientes que são gestores fez questão de reconhecer e afirmar a importância daquele gesto ali materializado na forma de doação às pessoas com necessidades básicas de sobrevivência e que precisam do olhar de caridade da sociedade, não só nesse momento duro que estamos a atravessar. Além disso, os discentes envolvidos sentiram tocados com as falas e reportaram que entendem que a qualquer época é dever cívico da universidade e seu corpo profissional endereçar à sociedade retribuições assim, na forma de projetos de extensão, como este e/ou outros tantos possíveis.

\section{CONSIDERAÇÕES FINAIS}

Após seis meses do seu início, o trabalho foi finalizado e teve-se a satisfação, enquanto docentes em nossa instituição, de oportunizar a três jovens uma formação 
diferenciada em relação aos demais que não se dispuseram ou não se dispõem a engajar em projetos de extensão. Vale ressaltar que os professores também saem renovados ao final do trabalho, pois toda ação nova traz novas experiências, novas vivências, novas perspectivas que fazem com que transformações ocorram, além é claro, da gratificante, direta e imediata retribuição da sociedade quando se adere a projetos como este.

Para além do acréscimo na formação acadêmica e profissional dos discentes, a participação deles nesse ato trouxe como principal benefício o empenho em uma ação concreta de enfrentamento a problemas sociais relevantes, cujo objetivo tratou-se de minimizar as desigualdades sociais em prol de uma sociedade mais justa e humana. Além disso, a oportunidade de aplicar os conhecimentos científicos adquiridos durante suas formações, foi também uma possibilidade recompensadora de reforçar o aprendizado, bem como dar um retorno à sociedade daquilo que "ela" investiu em suas formações.

Há também ganhos institucionais imensuráveis, dado que ao promover tais ações a nossa instituição se estabelece mais uma vez, local e nacionalmente, como entidade de referência alinhada ao enfrentamento e solução de problemas apresentados pela sociedade. Isto traz, sem dúvidas, um impacto positivo de grande valor para a imagem do nosso campus perante a opinião pública, dado que, ao cumprir qualquer aspecto de sua função social, muda a configuração de cenários como este relacionado à Covid-19. Portanto, ao atender às demandas sociais, a instituição de ensino atinge de forma inquestionável parte de suas metas historicamente estabelecidas no Plano de Desenvolvimento Institucional.

\section{Agradecimentos}

Os autores agradecem à DEDC, pelo apoio e financiamento deste projeto de extensão. Os agradecimentos também se estendem ao PET - Engenharia de Minas do nosso campus por todo apoio na execução do projeto.

\section{REFERÊNCIAS}

ANVISA. Agência Nacional de Vigilância Sanitária - NOTA TÉCNICA № 3/2020/SEI/DIRE3/ANVISA. Atualizado em 24 de março de 2020.

ASSIS, K. S.; SACCHELLI, C. M. A importância da realização de projetos de extensão comunitária pelo grupo pet. In: XLVIII Congresso Brasileiro de Educação em Engenharia (COBENGE), 2020, Caxias do Sul. Anais. Caxias do Sul (on line). Disponível em: http://abenge.org.br/sis artigo doi.php? $==C O B E N G E \& a=20 \& c=3014$. Acesso em 23 abr. 2021.

BRASIL. Lei de Diretrizes e Bases da Educação Nacional, LDB. 9394/1996.

BRASIL. Agência Nacional de Vigilância Sanitária. Comissão da Farmacopeia Brasileira. Formulário Nacional da Farmacopeia Brasileira. $2^{\underline{a}}$ edição. Revisão 02. Brasília: Agência Nacional de Vigilância Sanitária, 2012.

EDITAL de Extensão: projetos de extensão. Disponível em: http://www.dedc.cefetmg.br/wpcontent/uploads/sites/79/2020/04/Edital 2020.32 COVID-19.pdf. Acesso em 23 abr. 2021. 
CHAKRABORTY, I.; MAITY, P. COVID-19 outbreak: Migration, effects on society, global environment and prevention. Science of the Total Environment, v. 728, 2020.

HAIDER, Syed, I.; ASIF, Erfan, S.. Quality Operations Procedures for Pharmaceutical, API and Biotechnology. Florida: CRC Press Taylor \& Francis Group, 2012.

RODRIGUES, C. C.; LIMA, A. F. M. L.; NOGUEIRA, F. C.; PEREIRA, C. A. A Extensão Universitária como Espaço de Formação Profissional. In: XLV Congresso Brasileiro de Educação em Engenharia (COBENGE), 2017, Joinvile. Anais. Joinvile. Disponível em: http://abenge.org.br/sis artigo doi.php?e=COBENGE\&a $=17 \& \mathrm{c}=58$. Acesso em 23 abr. 2021.

\title{
THE RELEVANT ROLE OF UNIVERSITY EXTENSION: A CASE REPORT IN THE PRODUCTION OF ALCOHOL-GEL FOR DONATION TO VULNERABLES IN THE FIGHT AGAINST CORONAVIRUS
}

\begin{abstract}
In extension activities, students can give civil society something relevant and thus seek less social inequality. In addition to quality education and research training, it is essential that the student be able to work on the knowledge acquired in the form of extension projects, as it is in them that effective actions for the most vulnerable citizens are often highlighted. Therefore, being prepared to respond to the most urgent needs in terms of social demand, as well as academic training, is an essential condition for achieving a level of excellence in our universities. In this context of meeting social demands, the project's main objective was to produce alcohol-gel 70INPM for skin asepsis and surface disinfection and to donate production to nursing homes and care homes for vulnerable people in the cities of Araxá-MG and Perdizes- MG. It is worth mentioning that the action of training more collaborative and sensitive individuals to the needs of the neediest transcends the objective of producing and delivering alcohol-gel. The execution of the project had the contribution of two professors and three students from our educational institution. The development of the project had several stages, such as: study of the project, production of the packaging label, survey of the production route (the formulation was adopted as recommended in the Brazilian Pharmacopoeia National Form), elaboration of eight Standard Operating Procedures (POP's), technical and safety training of the team, the effective production of 70 -INPM alcohol-gel and the delivery of production to the benefited establishments. Because of the students, in addition to all the technical and theoretical work in addition to their professional academic training, their participation in this act brought as a main benefit the engagement in a concrete action to confront relevant social problems. Teachers are assured of renewal at the end of the work, as every new action brings new experiences, new experiences, new perspectives that make transformations occur and the return to society is direct and immediate when joining extension projects.
\end{abstract}

Keywords: Extension project, coronavirus, alcohol-gel 70\% (w/w), complementary training. 